\title{
Dietary cholesterol and egg yolk should be avoided by patients at risk of vascular disease
}

\author{
J. David Spence \\ Stroke Prevention and Atherosclerosis Research Centre, Robarts Research Institute, \\ Western University, London, ON N6G 2V2, Canada
}

\begin{abstract}
Recent recommendations that limits to dietary cholesterol be dropped were probably heavily influenced by propaganda from the egg industry. After conviction for false advertising, the industry has spent hundreds of millions of dollars to convince the public, physicians, and policy makers that dietary cholesterol and egg yolk are harmless. However, there are good reasons for longstanding recommendations that dietary cholesterol be limited to <200 $\mathrm{mg} /$ day in persons at risk of vascular disease. It is seldom understood that this essentially means all people in developed countries who expect to attain an advanced age. There is abundant evidence that dietary cholesterol increases cardiovascular risk. The misdirection of the egg industry focuses on fasting levels of LDL cholesterol, which are only raised by $\sim 10 \%$ by consumption of egg yolks. However, the main effect of diet is on the post-prandial state: for 4 hours after a high fat/high cholesterol meal, there is oxidative stress, endothelial dysfunction, and arterial inflammation. One large $(65 \mathrm{~g})$ egg yolk contains $237 \mathrm{mg}$ of cholesterol, well above the recommended limit-nearly as much as a 12-ounce hamburger. Besides the very high cholesterol content of egg yolk, the phosphatidylcholine in egg yolk leads, via action of the intestinal microbiome, to production of trimethylamine n-oxide (TMAO), which causes atherosclerosis in animal models. Levels of TMAO in the top quartile after a test dose of two egg yolks were associated with a 2.5-fold increase in the 3-year risk of stroke, death, or myocardial infarction among patients referred for coronary angiography. Persons at risk of cardiovascular disease should limit their intake of cholesterol and egg yolk.
\end{abstract}

Key words: diet, cholesterol, egg yolk, cardiovascular risk

Address for Correspondence:

J. David Spence,

Stroke Prevention and Atherosclerosis Research Centre, Robarts Research Institute, Western University, London,

ON N6G 2V2, Canada.

Email: dspence@robarts.ca

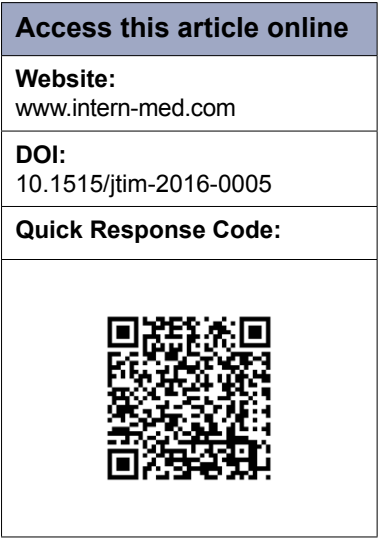

The following is adapted from a commentary in the International Atherosclerosis Society online educational material, at http://www.athero.org/ commentaries/comm1145.asp, and from a submission to the US Department of Health Promotion and Disease Prevention in March, 2015.

In 2015, an advisory panel recommended to the United States Office of Disease Prevention and Health Promotion that limits on dietary cholesterol be dropped.

It is very likely that the recommendation of the advisory panel was heavily influenced by propaganda from the egg industry.
As documented by Dr. Michael Greger, the egg industry has spent hundreds of millions of dollars on propaganda, following a conviction for false advertising and loss of the appeal in the US Supreme Court. (http://nutritionfacts.org/video/ eggs-and-cholesterol-patently-false-andmisleading-claims/).

The remarkable success of egg marketing propaganda has led to widespread belief that dietary cholesterol and consumption of egg yolks are harmless. For the sake of patients at risk of cardiovascular events, it is important to recognize this propaganda for what it is. 
Spence: Dietary cholesterol and egg yolk: not recommended for patients at risk of vascular disease

Propaganda is described on Wikipedia as follows: "Propaganda is a form of communication that is aimed towards influencing the attitude of a community toward some cause or position by presenting only one side of an argument. Propaganda is usually repeated and dispersed over a wide variety of media in order to create the chosen result in audience attitudes.

As opposed to impartially providing information, propaganda, in its most basic sense, presents information primarily to influence an audience. Propaganda often presents facts selectively (thus possibly lying by omission) to encourage a particular synthesis, or uses loaded messages to produce an emotional rather than rational response to the information presented. The desired result is a change of the attitude toward the subject in the target audience to further a political, religious, or commercial agenda. Propaganda can be used as a form of ideological or commercial warfare."

The propaganda of the egg industry rests on a red herring, and a half-truth. The red herring is a misplaced focus on elevated fasting levels of LDL cholesterol as the main or only harmful effect of dietary cholesterol. The half-truth is the slogan "eggs can be part of a healthy diet for healthy people."

\section{DIETARY CHOLESTEROL AND CARDIOVASCULAR RISK}

There are good reasons for the longstanding recommendation ${ }^{[1,2]}$ that patients at risk of vascular disease should reduce dietary cholesterol below $200 \mathrm{mg}$ /day. The 2011 European guideline on dyslipidemia ${ }^{[3]}$ recommends egg whites in place of whole eggs. In both the Ireland-Boston Diet-Heart Study ${ }^{[4]}$ and the Western Electric study ${ }^{[5]}$, dietary cholesterol increased cardiovascular risk. In a British study of health-conscious individuals ${ }^{[6]}$, both dietary cholesterol and egg consumption significantly increased coronary risk. In animal models, dietary cholesterol causes atherosclerosis ${ }^{[7-9]}$.

A single jumbo (65 g) egg yolk contains $237 \mathrm{mg}$ of cholesterol. This is more than the recommended daily intake of cholesterol, and nearly as much as the $275 \mathrm{mg}$ of cholesterol in the dietary monstrosity, the Hardee's Monster Thickburger, which contains 12 ounces of beef, three slices of cheese, and four slices of bacon. Obviously the burger, which also contains saturated fat, is more harmful than the egg yolk, but the huge cholesterol content of egg yolks means that egg yolks should not regularly be consumed by persons at risk of vascular disease. As discussed below, there is more to the harm from egg yolks than the very high cholesterol content.

\section{THE HALF-TRUTH}

Egg marketers repeatedly say that studies have not shown harm from egg yolk consumption among healthy people. This is based on two US studies ${ }^{[10,11]}$ that enrolled healthy people, followed them over time, and did not find harm from egg yolk consumption among those who remained healthy. The second part of the story, never mentioned by the egg marketers, is that both those studies showed that among people who became diabetic during follow-up, an egg a day doubled coronary risk. It is likely that failure to show harm from eggs among persons who remained healthy during follow-up was lack of statistical power: in the US Health Professionals study, women age $\sim 45$ at baseline were followed for 14 years, and men age $\sim 52$ at baseline were followed for 8 years.

Furthermore, the US diet is so bad that in Americans, it is difficult to show harm from egg consumption. The 2015 statistical report of the American Heart Association ${ }^{[12]}$ showed that diet is the worst lifestyle issue for Americans: fewer than 10\% of Americans eat a healthy diet. A recent global study of dietary patterns showed that the two countries with the highest intake of unhealthy foods were Russia and the United States ${ }^{[13]}$. Rose $^{[14]}$ described the problem of "sick individuals and sick populations."

In Greece, where the diet is much more healthy, it was easier to show harm from egg consumption. A study by Trichopoulou et al. in Greek diabetics showed that an egg a day increased coronary risk 5-fold, and each $10 \mathrm{~g}$ of egg per day (about a $6^{\text {th }}$ of a large egg) doubled cardiovascular risk. Egg consumption also increases the risk of diabetes ${ }^{[15]}$, and of congestive heart failure ${ }^{[16]}$.

At the 2015 International Stroke Conference of the American Heart Association, I presented a paper ${ }^{[17]}$ showing that among participants in the NIH-funded study on racial, ethnic, and geographical differences in stroke (REGARDS) that dietary cholesterol and egg consumption significantly predicted the risk of atherosclerotic events (myocardial infarction, stroke, and revascularization).

An issue that is seldom discussed is what constitutes such a low risk that it would justify the safe consumption of high-cholesterol meals, including egg yolks. In North America, all of us who live long enough are at high risk of cardiovascular events. A young man might feel it was safe to smoke and eat egg yolks because his myocardial infarction is some 40 years in the future-but why would he want to accelerate his atherosclerosis and thereby bring it on sooner? ${ }^{[18]}$ 
Spence: Dietary cholesterol and egg yolk: not recommended for patients at risk of vascular disease

\section{DIET IS ABOUT THE POST-PRANDIAL STATE}

Dietary cholesterol and egg yolks do raise fasting levels of LDL cholesterol, by around 10\%, in a dose-dependent manner ${ }^{[19,20]}$ However, the level of cholesterol first thing in the morning, after an overnight fast, tells us what the endothelium was exposed to for the last few hours of the night; it can be regarded as a baseline, on top of which post-prandial effects can be seen ${ }^{[21]}$. Fasting cholesterol levels are determined mainly by heredity, insulin resistance ${ }^{[22,23]}$, obesity, and factors other than what was consumed the previous day. The widespread emphasis on saturated fat as the main determinant of fasting levels of LDL is also misplaced: dietary cholesterol is permissive of the effects of saturated fat on fasting lipid levels ${ }^{[24]}$. Saturated fat has a much greater effect on fasting LDL when it is consumed with cholesterol ${ }^{[24]}$; this has been called the "bacon and egg" effect ${ }^{[25]}$. Recent analyses suggesting that saturated fat may not be harmful were therefore overly simplistic: effects of saturated fat must be considered in relation to cholesterol intake.

Much more important than the effects on fasting lipids are the post-prandial effects ${ }^{[25]}$. Dietary cholesterol above $140 \mathrm{mg}$ in a single meal markedly potentiates post-prandial lipemia ${ }^{[2]}$. High dietary intake of cholesterol increases LDL oxidation by nearly $40 \%{ }^{[27,28]}$, and impairs endothelial function for several hours, probably through oxidative stress ${ }^{[29-31]}$. A high-cholesterol meal increases vascular inflammation for several hours ${ }^{[32]}$, and an egg-white-based substitute improved endothelial function compared with whole eggs ${ }^{[33]}$.

\section{EFFECT OF EGG YOLKS ON CAROTID ATHEROSCLEROSIS}

In a study of 1206 patients attending vascular prevention clinics, Spence et al. ${ }^{[34]}$ found that egg yolk consumption accelerated carotid atherosclerosis in a fashion similar to the effect of smoking. In linear regression, the effect of egg consumption was independent of sex, serum cholesterol, smoking, blood pressure, and body mass index. Furthermore, the effect of egg consumption and smoking appeared to be additive ${ }^{[18]}$, with egg consumption alone having approximately $60 \%$ of the effect of smoking alone. New evidence, discussed below, suggests that the harmful effects of egg yolk on the arteries may not be dependent on the high cholesterol content alone.

\section{HARM OF EGG YOLKS: BEYOND CHOLESTEROL}

It is increasingly understood that the intestinal microbiome has profound metabolic effects on the host ${ }^{[35]}$. Two landmark papers from Hazen's group now make it clear that besides cholesterol, phosphatidylcholine (lecithin) is another important ingredient in egg yolks that causes vascular harm. Dietary phosphatidylcholine is converted by intestinal bacteria to trimethylamine, which is oxidized in the liver to trimethylamine n-oxide (TMAO). Wang et al. ${ }^{[36]}$ showed in 2011 that TMAO was pro-atherosclerotic in a mouse model, and was associated with vascular disease in patients. In 2013, they discussed the complex genetic and dietary regulation of $\mathrm{TMAO}^{[37]}$. Recently, they confirmed in human subjects the obligatory role of intestinal flora in converting phosphatidylcholine to TMAO, and showed in patients referred for coronary angiography ${ }^{[38]}$ that TMAO levels in the top quartile increased major cardiovascular events 2.5 -fold, after adjustment for traditional coronary risk factors. Similarly, Hazen's group recently showed ${ }^{[39]}$ that L-carnitine in red meat also increases TMAO through the action of intestinal bacteria.

These revolutionary findings now open the door for new approaches to cardiovascular prevention, via manipulation of the intestinal microbiome by macrobiotics ${ }^{[40]}$, or perhaps targeted replacement of harmful intestinal flora with panels of beneficial flora ${ }^{[41]}$.

The role of bile acids in flavin monooxygenase- 3 induced oxidation of trimethylamine to $\mathrm{TMAO}^{[37]}$ raises the possibility that therapies such as bile acid sequestrants and ezetimibe might act in part via this mechanism. These new findings also raise the possibility that trimethylamine and TMAO might play a role in the high cardiovascular risk of renal failure.

The very high cardiovascular risk of patients in renal failure is probably related to elevations of total homocysteine and asymmetric dimethylarginine ${ }^{[42]}$. The recognition that TMAO increases cardiovascular risk now opens a new chapter in this story. Trimethylamine, thought to explain the fishy odor of patients with renal failure ${ }^{[43]}$, accumulates in renal failure ${ }^{[44]}$. All the foregoing suggests that patients in renal failure should particularly avoid foods high in carnitine and phosphatidylcholine, such as egg yolk and red meat, and that they may be candidates for treatments to replace harmful intestinal bacteria with beneficial intestinal microbiota $^{[45]}$.

\section{CONCLUSIONS}

Dietary cholesterol and egg yolks have important harmful effects in the post-prandial state, and increase the risk of cardiovascular events. New understanding of the role of the intestinal microbiome will revolutionize our approaches to diet and cardiovascular disease. Regular consumption of egg yolks should be avoided by people at risk of 
cardiovascular disease, which essentially means all North Americans who expect to live past middle age. "Stopping the consumption of egg yolks after a stroke or myocardial infarction would be like quitting smoking after a diagnosis of lung cancer."[25]

\section{Conflicts of Interest}

None declared.

\section{REFERENCES}

1. Healthy People 2000: National Health Promotion and Disease Prevention Objectives. United States Department of Health and Human Services; 1991.

2. Adult Treatment Panel III. Third Report of the National Cholesterol Education Program (NCEP) Expert Panel on Detection, Evaluation, and Treatment of High Blood Cholesterol in Adults (Adult Treatment Panel III) final report. Circulation 2002;106:3143-421.

3. Catapano AL, Reiner Z, De BG, Graham I, Taskinen MR, Wiklund O, et al. ESC/EAS Guidelines for the management of dyslipidaemias: the Task Force for the management of dyslipidaemias of the European Society of Cardiology (ESC) and the European Atherosclerosis Society (EAS). Atherosclerosis 2011;217 Suppl 1:S1-44.

4. Kushi LH, Lew RA, Stare FJ, Ellison CR, el LM, Bourke G, et al. Diet and 20-year mortality from coronary heart disease. The Ireland-Boston Diet-Heart Study. N Engl J Med 1985;312:811-8.

5. Shekelle RB, Shryock AM, Paul O, Lepper M, Stamler J, Liu S, et al. Diet, serum cholesterol, and death from coronary heart disease. The Western Electric study. N Engl J Med 1981;304:65-70.

6. Mann JI, Appleby PN, Key TJ, Thorogood M. Dietary determinants of ischaemic heart disease in health conscious individuals. Heart 1997;78:450-5.

7. ANDRUS SB, MANN GV. Xanthomatosis and atherosclerosis produced by diet in an adult rhesus monkey. J Lab Clin Med 1956;48:533-50.

8. Finking G, Hanke H. NikolajNikolajewitschAnitschkow (1885-1964) established the cholesterol-fed rabbit as a model for atherosclerosis research. Atherosclerosis 1997;135:1-7.

9. Gresham Ga, Leat Wm, Howard An, Jennings Iw. Pathological Changes In Pigs Reared On Semi-Synthetic Diets Containing No Fat, Beef Tallow And Maize Oil. Br J ExpPathol 1964;45:128-34.

10. Hu FB, Stampfer MJ, Rimm EB, Manson JE, Ascherio A, Colditz GA, et al. A prospective study of egg consumption and risk of cardiovascular disease in men and women. JAMA 1999;281:1387-94.

11. Qureshi AI, Suri FK, Ahmed S, Nasar A, Divani AA, Kirmani JF. Regular egg consumption does not increase the risk of stroke and cardiovascular diseases. Med SciMonit 2007;13:CR1-CR8.

12. Mozaffarian D, Benjamin EJ, Go AS, Arnett DK, Blaha MJ, Cushman M, et al. Heart disease and stroke statistics-2015 update: a report from the american heart association. Circulation 2015;131:e29-e322.

13. Imamura F, Micha R, Khatibzadeh S, Fahimi S, Shi P, Powles J, et al. Dietary quality among men and women in 187 countries in 1990 and 2010: a systematic assessment. Lancet Glob Health 2015;3:e132-42.

14. Rose G. Sick individuals and sick populations. Int J Epidemiol 2001;30:427-32.

15. Djousse L, Gaziano JM, Buring JE, Lee IM. Egg consumption and risk of type 2 diabetes in men and women. Diabetes Care 2009;32:295-300.

16. Djousse L, Gaziano JM. Egg consumption and risk of heart failure in the Physicians' Health Study. Circulation 2008;117:512-6.

17. Spence JD, Judd SE, Howard VJ, Safford M, Howard G. Effect of Dietary Cholesterol and Egg Consumption On Mortality And Cardiovascular Risk in the REGARDS Study. Stroke 2015; 46: A83.
18. Spence JD, Jenkins DJA, Davignon J. Egg yolk consumption, smoking and carotid plaque: Reply to Letters to the Editor by Sean Lucan and T Dylan Olver et al. Atherosclerosis 2013;227:189-91.

19. Sacks FM, Salazar J, Miller L, Foster JM, Sutherland M, Samonds KW, et al. Ingestion of egg raises plasma low density lipoproteins in free-living subjects. Lancet 1984;1:647-9.

20. Ginsberg HN, Karmally W, Siddiqui M, Holleran S, Tall AR, Rumsey SC, et al. A dose-response study of the effects of dietary cholesterol on fasting and postprandial lipid and lipoprotein metabolism in healthy young men. Arterioscler Thromb 1994;14:576-86.

21. Spence JD. Fasting lipids: the carrot in the snowman. Can J Cardiol 2003;19:890-2.

22. Tan KC, Cooper MB, Ling KL, Griffin BA, Freeman DJ, Packard CJ, et al. Fasting and postprandial determinants for the occurrence of small dense LDL species in non-insulin-dependent diabetic patients with and without hypertriglyceridaemia: the involvement of insulin, insulin precursor species and insulin resistance. Atherosclerosis 1995;113:273-87.

23. Tan KC, Tso AW, Ma OC, Pang RW, Tam S, Lam KS. Determinants of postprandial triglyceride and remnant-like lipoproteins in type 2 diabetes. Diabetes Metab Res Rev 2005;21:209-14.

24. Fielding CJ, Havel RJ, Todd KM, Yeo KE, Schloetter MC, Weinberg V, et al. Effects of dietary cholesterol and fat saturation on plasma lipoproteins in an ethnically diverse population of healthy young men. J Clin Invest 1995;95:611-8.

25. Spence JD, Jenkins DJ, Davignon J. Dietary cholesterol and egg yolks: Not for patients at risk of vascular disease. Can J Cardiol 2010;26:e336-9.

26. Dubois C, Armand M, Mekki N, Portugal H, Pauli AM, Bernard PM, et al. Effects of increasing amounts of dietary cholesterol on postprandial lipemia and lipoproteins in human subjects. J Lipid Res 1994;35:19932007.

27. Levy Y, Maor I, Presser D, Aviram M. Consumption of eggs with meals increases the susceptibility of human plasma and low-density lipoprotein to lipid peroxidation. Ann Nutr Metab 1996;40:243-51.

28. Schwab US, Ausman LM, Vogel S, Li Z, Lammi-Keefe CJ, Goldin BR, et al. Dietary cholesterol increases the susceptibility of low density lipoprotein to oxidative modification. Atherosclerosis 2000;149:83-90.

29. Terasaka N, Yu S, Yvan-Charvet L, Wang N, Mzhavia N, Langlois R, et al. ABCG1 and HDL protect against endothelial dysfunction in mice fed a high-cholesterol diet. J Clin Invest 2008;118:3701-13.

30. Vogel RA, Corretti MC, Plotnick GD. Effect of a single high-fat meal on endothelial function in healthy subjects. Am J Cardiol 1997;79:350-4.

31. Plotnick GD, Corretti MC, Vogel RA, Hesslink R, Jr., Wise JA. Effect of supplemental phytonutrients on impairment of the flow-mediated brachial artery vasoactivity after a single high-fat meal. J Am CollCardiol 2003;41:1744-9.

32. Ghanim H, Abuaysheh S, Sia CL, Korzeniewski K, Chaudhuri A, Fernandez-Real JM, et al. Increase in plasma endotoxin concentrations and the expression of Toll-like receptors and suppressor of cytokine signaling-3 in mononuclear cells after a high-fat, high-carbohydrate meal: implications for insulin resistance. Diabetes Care 2009;32:2281-7.

33. Njike V, Faridi Z, Dutta S, Gonzalez-Simon AL, Katz DL. Daily egg consumption in hyperlipidemic adults--effects on endothelial function and cardiovascular risk. Nutr J 2010;9:28.

34. Spence JD, Jenkins DJ, Davignon J. Egg yolk consumption and carotid plaque. Atherosclerosis 2012;224:469-73.

35. Clemente JC, Ursell LK, Parfrey LW, Knight R. The impact of the gut microbiota on human health: an integrative view. Cell 2012;148:1258-70.

36. Wang Z, Klipfell E, Bennett BJ, Koeth R, Levison BS, Dugar B, et al. Gut flora metabolism of phosphatidylcholine promotes cardiovascular disease. Nature 2011;472:57-63.

37. Bennett BJ, de Aguiar Vallim TQ, Wang Z, Shih DM, Meng Y, Gregory J, et al. Trimethylamine-N-oxide, a metabolite associated with atherosclerosis, exhibits complex genetic and dietary regulation. Cell Metab 2013;17:49-60. 
38. Tang WHW, Wang Z, Levinson BS, Koeth RA, Britt EB, Fu X, et al. Intestinal Microbiota Metabolism of Phosphatidylcholine and Incident Cardiac Risks. N Engl J Med 2013;368:1575-84.

39. Koeth RA, Wang Z, Levison BS, Buffa JA, Org E, Sheehy BT, et al. Intestinal microbiota metabolism of 1-carnitine, a nutrient in red meat, promotes atherosclerosis. Nat Med 2013;19:576-85.

40. Reid G, Younes JA, Van der Mei HC, Gloor GB, Knight R, Busscher HJ. Microbiota restoration: natural and supplemented recovery of human microbial communities. Nat Rev Microbiol 2011;9:27-38.

41. Brandt LJ, Aroniadis OC, Mellow M, Kanatzar A, Kelly C, Park T, et al. Long-term follow-up of colonoscopic fecal microbiota transplant for recurrent Clostridium difficile infection. Am J Gastroenterol 2012;107:1079-87.
42. Spence JD, Stampfer MJ. Understanding the complexity of homocysteine lowering with vitamins: the potential role of subgroup analyses. JAMA 2011;306:2610-1.

43. Simenhoff ML, Burke JF, Saukkonen JJ, Ordinario AT, Doty R. Biochemical profile of uremic breath. N Engl J Med 1977;297:132-5.

44. Meyer TW, Hostetter TH. Uremia. N Engl J Med 2007;357:1316-25.

45. Meyer TW, Hostetter TH. Uremic solutes from colon microbes. Kidney Int 2012;81:949-54.

How to cite this article: JSpence JD. Dietary cholesterol and egg yolk should be avoided by patients at risk of vascular disease. J Transl Intern Med 2016; 4: 20-4. 